\title{
Evaluation of a New Chemical Mechanism for 2- Amino-2-methyl-1-propanol in a Reactive Environment from CSIRO Smog Chamber Experiments
}

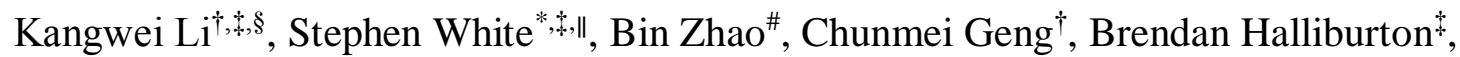
Zhibin Wang ${ }^{+}$, Yanyun Zhao ${ }^{\S}$, Hai Yu ${ }^{\$}$, Wen Yang ${ }^{\dagger}$, Zhipeng Bai* ${ }^{* \dagger}$, Merched Azzi ${ }^{*}$,

${ }^{\dagger}$ State Key Laboratory of Environmental Criteria and Risk Assessment, Chinese Research Academy of Environmental Sciences, Beijing 100012, China

*CSIRO Energy, PO Box 52, North Ryde, New South Wales 1670, Australia

$\S$ State Key Laboratory of Clean Energy Utilization, Zhejiang University, Hangzhou 310027, China

" New South Wales Department of Planning, Industry and Environment, PO Box 29, Lidcombe, New South Wales 1825, Australia

\# Pacific Northwest National Laboratory, Richland, Washington 99352, United States

+ Research Center for Air Pollution and Health, College of Environmental and Resource Sciences, Zhejiang University, Hangzhou 310058, China

\$CSIRO Energy, 10 Murray Dwyer Circuit, Mayfield West, New South Wales 2304, Australia

*Corresponding authors: Stephen.White@environment.nsw.gov.au (S. White), baizp@craes.org.cn (Z. Bai), merchedazzi004@gmail.com (M. Azzi)

\section{Supporting Information}

Number of pages: 27

Number of text sections: 5

Number of tables: 5

Number of figures: 13 


\section{Text S1 Comparison of SIFT-MS and in situ FTIR measurement}

As described in Table S1, five supplementary experiments were performed for a variety of purposes using 2-aminoethanol (MEA) and 2-amino-2-methyl-1-propanol (AMP), including the $\mathrm{MEA}+\mathrm{NOx} / \mathrm{H}_{2} \mathrm{O}_{2}$ experiments and $\mathrm{AMP}+\mathrm{H}_{2} \mathrm{O}_{2} / \mathrm{O}_{3} / \mathrm{NO}_{3}$ experiments. One purpose of these experiments was to examine the ability of selected ion flow tube mass spectrometry (SIFT-MS) to quantify amines by comparing the measurement from long-path Fourier-transform infrared spectroscopy (FTIR). Similar to previous literatures, ${ }^{1-3}$ a few blank experiments were conducted, where reference FTIR spectrum and linear relationship for MEA, AMP and $\mathrm{NH}_{3}$ were obtained via multiple injections into the chamber (the chamber was operated without UV lights) at different mixing ratios. SIFT-MS was regularly calibrated against gaseous standard containing 8 hydrocarbons. ${ }^{4}$ MEA, AMP, and $\mathrm{NH}_{3}$ were identified through $60^{+}\left(\mathrm{NO}^{+}\right)$, $90^{+}\left(\mathrm{H}_{3} \mathrm{O}^{+}\right)$, and $17^{+}\left(\mathrm{O}_{2}^{+}\right)$ions, and the raw signal of these ions were further scaled by calibration factors obtained from multiple chamber injections in the dark condition with known concentrations.

As shown in Fig. S3, MEA and AMP were measured by both FTIR and SIFT-MS for NR298 and NR306. Some inconsistency was observed for both measurements during amine injection and later during a static period. This phenomenon may be attributed to the different sampling techniques of FTIR and SIFT-MS. FTIR is an in situ technique that provides a real (non-sampled) gas-phase concentration, while SIFT-MS needs to use a sampling line connected to the chamber with a constant flow rate. Due to the featured physical property (low vapour pressure) of these amine compounds, amines may stick onto the sampling line, which may result in delay, slow equilibration or underestimation compared with the in situ FTIR technique. However, the decay process of amines was matched reasonably well by both measurements, which demonstrated that the quantification results of amines by SIFT-MS were reliable and qualitatively comparable under these conditions. 
Both MEA and AMP can produce $\mathrm{NH}_{3}$ through photo-oxidation in the presence of NOx or $\mathrm{H}_{2} \mathrm{O}_{2}$. The $\mathrm{NH}_{3}$ signal measured by SIFT-MS was higher overall than measured by FTIR, but both showed similar trends. As shown from NR298 and NR302, the estimated $\mathrm{NH}_{3}$ molar yield by MEA was $25 \sim 35 \%$, which was much higher than that of AMP. In addition, the aerosol formation from amine $+\mathrm{H}_{2} \mathrm{O}_{2}$ was much lower than in the presence of NOx, implying an important role for NOx in forming amine-relevant secondary aerosols. 


\section{Text S2 Determining rate constant of $\mathrm{AMP}+\mathrm{OH}$}

AMP can be emitted to the atmosphere as a vapour, where it is expected to react with $\mathrm{OH}, \mathrm{NO}_{3}$ and potentially with ozone. The primary loss of AMP from the gas phase occurs during the day by reaction with the $\mathrm{OH}$ radical. To our best knowledge, the only experimentally derived reaction rate constant of AMP with $\mathrm{OH}\left(k_{\mathrm{AMP}+\mathrm{OH}}\right)$ was reported nearly 40 years ago, which is $2.8 \times 10^{-11} \mathrm{~cm}^{3}$ molecule ${ }^{-1} \mathrm{~s}^{-1}$ at $298 \mathrm{~K}^{5}$ This value is slower than that of MEA with $\mathrm{OH}\left(k_{\mathrm{MEA}+\mathrm{OH}}\right)$, which is $7.61 \times 10^{-11} \mathrm{~cm}^{3}$ molecule ${ }^{-1} \mathrm{~s}^{-1}$ experimentally determined using laser-induced fluorescence technique. ${ }^{5}$ Such difference is also consistent with the different molecular structure of AMP and MEA. The structure-activity relationship (SAR) for amines also indicated that the predicted reactivity is directly related to the available adjacent hydrogens. ${ }^{7}$

There is a potential need to examine the reported rate constant of AMP with $\mathrm{OH}$, considering the uncertainty of reported value of $2.8 \times 10^{-11} \mathrm{~cm}^{3}$ molecule $\mathrm{e}^{-1} \mathrm{~s}^{-1}$ that obtained nearly 40 years ago. For this purpose, two supplementary experiments using MEA (NR302) and AMP (NR306) were conducted with $\mathrm{H}_{2} \mathrm{O}_{2}$ photo-oxidation to produce $\mathrm{OH}$ radical, aiming to estimate $k_{\mathrm{AMP}+\mathrm{OH}}$ based on relative rate method that using MEA as reference compound. As shown in Fig. S3, the decay rate of AMP from the $\mathrm{AMP}+\mathrm{H}_{2} \mathrm{O}_{2}$ experiment was slower than for MEA from the $\mathrm{MEA}+\mathrm{H}_{2} \mathrm{O}_{2}$ experiment, suggesting the faster rate constant of MEA with $\mathrm{OH}$ than that of AMP.

Here we assume the OH levels are same and constant for both NR302 and NR306. By linear fitting $\ln [\mathrm{MEA}]$ vs. [t] and $\ln [\mathrm{AMP}]$ vs. [ $\mathrm{t}]$ across the amine decay curves of NR302 and NR306 in Fig. S3, we could derive a ratio of $k_{\mathrm{AMP}+\mathrm{OH}} / k_{\mathrm{MEA}+\mathrm{OH}}=0.35$. Assuming $k_{\mathrm{MEA}+\mathrm{OH}}$ of $7.61 \times 10^{-11} \mathrm{~cm}^{3}$ molecule $\mathrm{s}^{-1}$, we can estimate the $k_{\mathrm{AMP}+\mathrm{OH}}$ of $2.66 \times 10^{-11} \mathrm{~cm}^{3}$ molecule ${ }^{-1} \mathrm{~s}^{-1}$, which agrees well with the reported value of $2.8 \times 10^{-}$ ${ }^{11} \mathrm{~cm}^{3}$ molecule $\mathrm{s}^{-1}$. Note that this is not a rigorous way for determining $k_{\mathrm{AMP}+\mathrm{OH}}$, and finally we still used the reported value in CSIAMP-19 mechanism. 


\section{Text S3 Determining of rate constant of $\mathrm{AMP}+\mathrm{O}_{3}$}

AMP could potentially react with $\mathrm{O}_{3}$, but no kinetic information available to our best knowledge. Here we performed a supplementary experiment (NR312) using AMP and $\mathrm{O}_{3}$, aiming to obtain the rate constant of $\mathrm{AMP}$ with $\mathrm{O}_{3}$ by monitoring the decay of $\mathrm{O}_{3}$. The results from $\mathrm{AMP}+\mathrm{O}_{3}$ experiment (NR312) are summarised in Fig. S4. It can be seen that some reactions did occur, as the loss of $\mathrm{O}_{3}$ was $\sim 10 \mathrm{ppbv}$ (reacted from $\sim 278$ to $\sim 269 \mathrm{ppbv}$ ) from 100 to $400 \mathrm{~min}$. In addition, no obvious products, except a small amount of aerosol $\left(<0.5 \mu \mathrm{g} \mathrm{m}^{-3}\right)$ were observed.

In this experiment (NR312), the remove process of $\mathrm{O}_{3}$ can be expressed as: $d\left[\mathrm{O}_{3}\right] / d \mathrm{t}=-\left(k_{\mathrm{AMP}+\mathrm{O} 3}[\mathrm{AMP}]+k_{\mathrm{O} 3 \text {,wall }}\right)\left[\mathrm{O}_{3}\right]$, where $k_{\mathrm{O} 3 \text {,wall }}$ is the first-order $\mathrm{O}_{3}$ chamber wall-loss rate, which was determined as $7 \times 10^{-7} \mathrm{~s}^{-1}$ in our chamber characterisation publication. ${ }^{8}$ Considering the slow reaction of $A M P$ with $\mathrm{O}_{3}$, the concentration of AMP was assumed constant as $\sim 200$ ppbv across the whole experiment. According to the decay curve of $\mathrm{O}_{3}$ in Fig. $\mathrm{S} 4$, a linear fitting to $\ln \left[\mathrm{O}_{3}\right]$ vs. [t] was performed. Then a reaction rate constant of $1.9 \times 10^{-19} \mathrm{~cm}^{3}$ molecule $\mathrm{s}^{-1}$ can be calculated. However, this is an order of magnitude lower than that of MEA with $\mathrm{O}_{3}\left(1.09 \times 10^{-18} \mathrm{~cm}^{3}\right.$ molecule ${ }^{-1}$ $\mathrm{s}^{-1}$ ) obtained by Borduas et al. ${ }^{9}$ Therefore, the reaction pathway of $\mathrm{AMP}+\mathrm{O}_{3}$ could be ignored due to the low reaction rate, and we do not consider it in our CSIAMP-19 mechanism. 


\section{Text S4 Exploring the reaction of $\mathrm{AMP}+\mathrm{NO}_{3}$}

AMP is likely to be removed by $\mathrm{NO}_{3}$ at night, and the product yields from the $\mathrm{AMP}+\mathrm{NO}_{3}$ reaction are assumed to be similar to those arising from the reaction with $\mathrm{OH}$. Here we performed a supplementary experiment (NR318) to explore the reaction of AMP with $\mathrm{NO}_{3}$ radical. We firstly injected $\mathrm{O}_{3}$ to about 350 ppbv, and then AMP was injected. $\mathrm{NO}_{2}$ injection was performed as the last procedure because $\mathrm{NO}_{3}$ radical would be formed rapidly from $\mathrm{NO}_{2}$ with $\mathrm{O}_{3}$. Thus once $\mathrm{NO}_{2}$ was injected into the chamber, $\mathrm{AMP}+\mathrm{NO}_{3}$ reaction was initiated.

The results from $\mathrm{AMP}+\mathrm{NO}_{3}(\mathrm{NR} 318)$ are summarised in Fig. S4, and it can be seen that instant aerosol formation and growth was observed on injection of $\mathrm{NO}_{2}$, with $>200 \mu \mathrm{g} \mathrm{m}^{-3}$ formed after $2 \mathrm{~h}$ of $\mathrm{NO}_{3}$ reaction. A strong signal of AMP nitramine $\left(164^{+}\left(\mathrm{NO}^{+}\right)\right)$was detected by SIFT-MS, and good correlation was observed between the loss of NOx $(\triangle \mathrm{NOx})$, increase of aerosol mass concentration, and AMP nitramine formation. This implies a potential connection between AMP nitramine and AMPderived aerosol, particularly for quick reactions, such as $\mathrm{AMP}+\mathrm{NO}_{3}$.

The fast decay of AMP indicates a quick reaction between $\mathrm{AMP}$ and $\mathrm{NO}_{3}$, but it is not feasible to obtain the rate constant of AMP with $\mathrm{NO}_{3}\left(k_{\mathrm{AMP}+\mathrm{NO} 3}\right)$ from this experiment, as the $\mathrm{NO}_{3}$ radical measurement is very difficult and unavailable at present. Nevertheless, we estimated $k_{\mathrm{AMP}+\mathrm{NO} 3}$ of $4.82 \times 10^{-14} \mathrm{~cm}^{3}$ molecule ${ }^{-1} \mathrm{~s}^{-1}$ using structureactivity relationship, which agrees well with that of $5.88 \times 10^{-14} \mathrm{~cm}^{3}$ molecule ${ }^{-1} \mathrm{~s}^{-1}$ used in CarterAMP-08 mechanism (see Table S3). ${ }^{10}$ 


\section{Text S5 AMP-derived aerosol formation}

AMP and the products arising from its photo-oxidation are expected to be partially removed from the atmosphere by partitioning into the aerosol phase, which could be the major loss processes. For example, high organic aerosol yields were determined using the Odum approach for the photo-oxidation of MEA. ${ }^{11}$ High amounts of aerosol have also been observed from both MEA and AMP photo-oxidation in a surrogate hydrocarbon mixture. ${ }^{10}$ The uptake of AMP by aqueous aerosol phase can also be an important path for AMP loss from the atmosphere. Some reviews ${ }^{7,12}$ have provided a useful overview of known partitioning behaviour of amines and nitrosamines into the aqueous phase, as well as radical-induced reactions that occur within the aqueous phase.

Amines can also react with gaseous nitric acid or sulfuric acid to form inorganic 'salt' aerosol. ${ }^{13,14}$ The aerosol formed in this process can reverse back to its gas-phase products. As such, the formation of amine-nitrate aerosol from the reaction of amine with nitric acid will be in competition with other inorganic aerosol formation processes, such as the reaction of $\mathrm{NH}_{3}$ and $\mathrm{HNO}_{3}$ to form ammonium nitrate. In chamber work on MEA, a substantial amount of $\mathrm{MEA}-\mathrm{HNO}_{3}$ (amine nitrate) aerosol forms under high NOx. ${ }^{15}$ These conditions are intended to replicate those likely to be found close to the emission. Therefore, it is expected that inorganic nitrate formation would also occur for AMP under these conditions. However, as these processes are expected to be reversible, a large amount of AMP may volatilise back into the gas phase before the aerosol is removed from the atmosphere by deposition.

Note that due to insufficient measurements of gaseous $\mathrm{HNO}_{3}$ and particle-phase composition, we are unable to justify the release of $\mathrm{NOx}_{\text {or }} \mathrm{HNO}_{3}$ from $\mathrm{AMP}$-derived aerosol in our experiments. Also, the equilibrium constants for amine salt are still unknown. Thus, we simply assume the reaction between $\mathrm{AMP}$ and $\mathrm{HNO}_{3}$ is rapid and irreversible in CSIAMP-19, followed by the same treatment of Carter. ${ }^{10}$

Table S1 Initial conditions of MEA and AMP supplementary experiments for deriving 
a new AMP chemical mechanism

\begin{tabular}{cccccccc}
\hline Expt ID & Reaction & Amine & $\mathrm{NO}$ & $\mathrm{NO}_{2}$ & $\mathrm{NOx}$ & $\mathrm{H}_{2} \mathrm{O}_{2}$ & $\mathrm{O}_{3}$ \\
& & ppbv & ppbv & ppbv & ppbv & ppmv & ppbv \\
\hline $\mathrm{NR} 298$ & $\mathrm{MEA}+\mathrm{NOx}$ & $\sim 522.6$ & $\sim 22$ & $\sim 7$ & $\sim 29$ & - & - \\
$\mathrm{NR} 302$ & $\mathrm{MEA}+\mathrm{H}_{2} \mathrm{O}_{2}$ & $\sim 241.3$ & - & - & - & $\sim 4.8$ & - \\
$\mathrm{NR} 306$ & $\mathrm{AMP}+\mathrm{H}_{2} \mathrm{O}_{2}$ & $\sim 153.4$ & - & - & - & $\sim 6.9$ & - \\
$\mathrm{NR} 312$ & $\mathrm{AMP}+\mathrm{O}_{3}$ & $\sim 197.4$ & - & - & - & - & $\sim 282$ \\
$\mathrm{NR318}$ & $\mathrm{AMP}+\mathrm{NO}_{3}$ & $\sim 97.5$ & - & $\sim 40$ & $\sim 40$ & - & $\sim 342$ \\
\hline
\end{tabular}

Note: Initial amine and $\mathrm{H}_{2} \mathrm{O}_{2}$ concentrations were estimated based on fully injection amount. 
Table S2 Chemical mechanisms used to simulate smog chamber experiments

\begin{tabular}{lll}
\hline Description & Base mechanism & Reference \\
\hline SAPRC-11 (base) & SAPRC-11 & Carter and Heo. ${ }^{16}$ \\
CB6 (base) & CB6 & Yarwood et al. $^{17}$ \\
SAPRC-11+CarterAMP-08 & SAPRC-11 & AMP mechanism from Carter. ${ }^{10}$ \\
CB6+CSIAMP-19 & CB6 & New AMP mechanism from this work \\
\hline
\end{tabular}


Table S3 AMP mechanism from Carter. ${ }^{10}$

\begin{tabular}{|l|l|r|}
\hline $\mathbf{R}$ & Reactions & Rate* \\
\hline 1 & $\begin{array}{l}\mathrm{AMP}+\mathrm{OH} \rightarrow \# .185 \mathrm{HO}_{2}+\# .799 \mathrm{NRAD}+\# .015 \mathrm{RO} 2 \mathrm{C}+\# .001 \\
\mathrm{RO} 2 \mathrm{XC}+\# .001 \mathrm{zRNO}_{3}+\# .185 \mathrm{RCHO}+\# .015 \mathrm{xHO}_{2}+\# .015 \\
\text { xRCHO }+\# .016 \mathrm{yROOH}+\# .201 \mathrm{XN}+\# .199 \mathrm{XC}\end{array}$ & $2.8 \times 10^{-11}$ \\
\hline 2 & $\mathrm{AMP}+\mathrm{NO}_{3} \rightarrow \mathrm{HNO}_{3}+\mathrm{NRAD}$ & $5.88 \times 10^{-14}$ \\
\hline 3 & $\mathrm{NRAD}+\mathrm{NO}_{2} \rightarrow \mathrm{PROD}+\# 2 \mathrm{XN}+\#-2 \mathrm{XC}$ & $1.21 \times 10^{-11}$ \\
\hline 4 & $\mathrm{NRAD}+\mathrm{NO} \rightarrow$ nitrosamine & Neglected \\
\hline 5 & $\mathrm{NRAD}+\mathrm{HO}_{2} \rightarrow \# 4 \mathrm{XC}+\mathrm{XN}$ & $5.2 \times 10^{-13}$ \\
\hline 6 & $\mathrm{AMP}+\mathrm{HNO}_{3} \rightarrow \# 4 \mathrm{XC}+\mathrm{XN}$ & $4.0 \times 10^{-11}$ \\
\hline
\end{tabular}

*The reaction rate constant: $\mathrm{cm}^{3}$ molecule ${ }^{-1} \mathrm{~s}^{-1}$ 
Table S4 Summary of key product data for VOC-NOx and AMP-VOC-NOx experiments (changes from initial amount/concentration at $\sim 6 \mathrm{~h}$ )

\begin{tabular}{|c|c|c|c|c|c|c|c|c|c|c|c|}
\hline Expt ID & $\begin{array}{c}\text { initial AMP } \\
\text { ppbv }\end{array}$ & $\begin{array}{c}\mathrm{O}_{3} \\
\mathrm{ppbv}\end{array}$ & $\begin{array}{l}\text { HCHO } \\
\text { ppbv }\end{array}$ & $\begin{array}{l}\mathrm{NH}_{3} \\
\mathrm{ppbv}\end{array}$ & $\begin{array}{l}\text { AMP } \\
\text { \% lost }\end{array}$ & $\begin{array}{l}\text { isoprene } \\
\% \text { lost }\end{array}$ & $\begin{array}{c}m \text {-xylene } \\
\% \text { lost }\end{array}$ & $\begin{array}{c}i \text {-pentane } \\
\% \text { lost }\end{array}$ & $\begin{array}{l}\text { aerosol } \\
\mu \mathrm{g} / \mathrm{m}^{3}\end{array}$ & $\begin{array}{l}\mathrm{NH}_{3} \\
\text { yield }\end{array}$ & $\begin{array}{c}\text { aerosol } \\
\text { yield }\end{array}$ \\
\hline \multicolumn{12}{|c|}{ VOC-NOx experiments } \\
\hline NR249 & - & 187.9 & 62.1 & - & - & 99 & 70 & 12 & 6.8 & - & - \\
\hline NR270 & - & 187.9 & 55.9 & - & - & 99 & 69 & 13 & 6.3 & - & - \\
\hline NR273 & - & 186.5 & 43.9 & - & - & 99 & 75 & 28 & 6.5 & - & - \\
\hline NR274 & - & 195.0 & 55.6 & - & - & 99 & 69 & 10 & 6.2 & - & - \\
\hline NR325 & - & 203.3 & 50.3 & - & - & 99 & 66 & 8 & 7.0 & - & - \\
\hline \multicolumn{12}{|c|}{ AMP-VOC-NOx experiments } \\
\hline NR281 & 68.2 & 143.7 & 51.1 & 0.6 & 54 & 95 & 49 & 3 & 108.2 & 0.02 & 0.83 \\
\hline NR329 & 34.8 & 152.2 & 36.7 & 1.2 & 63 & 96 & 53 & 7 & 87.4 & 0.05 & 1.11 \\
\hline NR332 & 19.1 & 182.8 & 52.6 & 0.5 & 53 & 98 & 59 & 9 & 49.5 & 0.05 & 1.36 \\
\hline NR338 & 27.3 & 171.7 & 39.4 & 1.8 & 71 & 98 & 60 & 19 & 64.7 & 0.09 & 0.93 \\
\hline
\end{tabular}

Note: $\mathrm{NH}_{3}$ yield refers to molar yield, and aerosol yield refers to mass yield (only relative to AMP loss). The aerosol mass concentrations were calculated with particle wall-loss correction. 
Table S5 List of species and lumped products in the new AMP reaction scheme

\begin{tabular}{|l|l|l|}
\hline Names & Species & Identified \\
\hline AMP & 2-amino-2-methyl-1-propanol & Yes (base amine) \\
\hline AMPN & Amino radical of AMP & No (radicals not observed) \\
\hline AMPR & Peroxy radical of AMP & No (radicals not observed) \\
\hline AMPNTR & Aerosol nitrate of AMP & Indirectly observed from SMPS measurement \\
\hline AMPNO & Nitrosamine of AMP & No (nitrosamine hard to observe) \\
\hline AMPNO 2 & Nitramine of AMP & Observed by SIFT-MS, but hard to quantify \\
\hline ISPD & Methallyl alcohol and other products & No \\
\hline
\end{tabular}

Note: ISPD is a CB6 model species, and here mainly representing as a C4 degradation product (methallyl alcohol) of AMP according to Antonsen et al. ${ }^{18}$ 

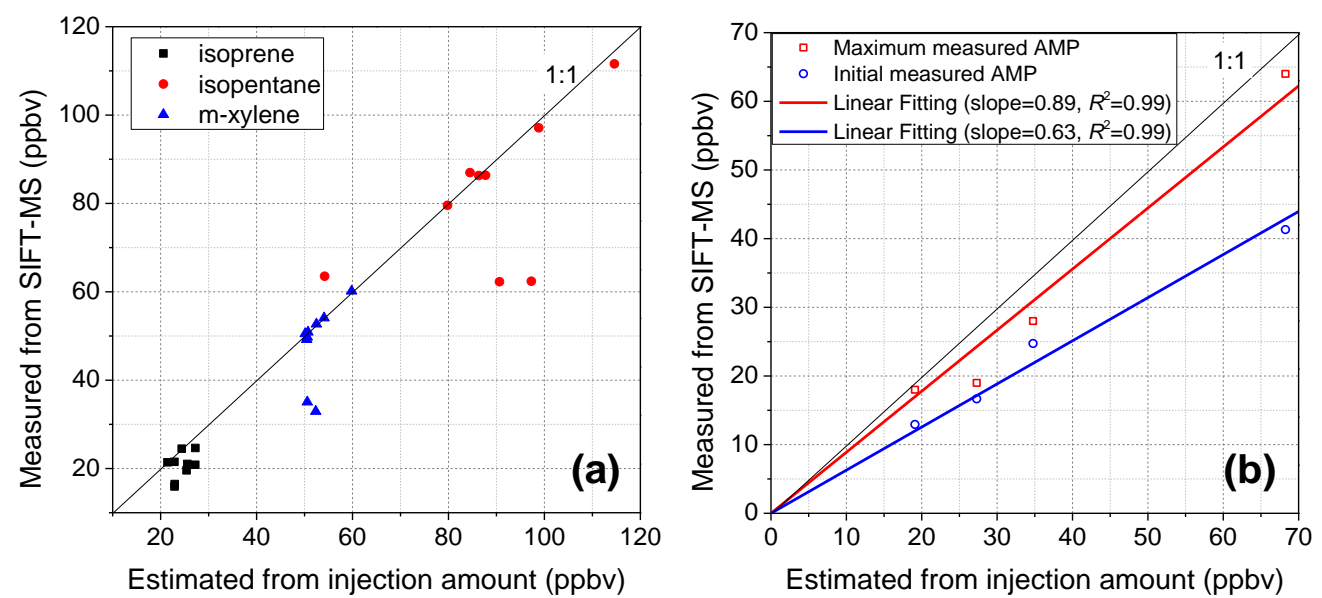

Figure S1 (a) Measured initial concentration vs. estimated initial concentration of isoprene, isopentane and $m$-xylene; (b) Measured initial/maximum concentration vs estimated initial concentration of AMP 


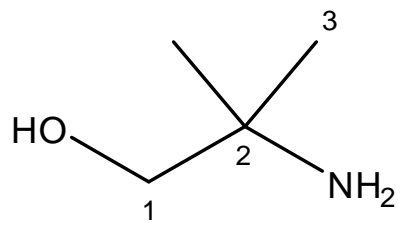

2-amino-2-methyl-1-propanol (AMP)<smiles>NCCO</smiles>

2-aminoe thanol (MEA)

Figure S2 Numbered chemical structures for AMP and MEA 

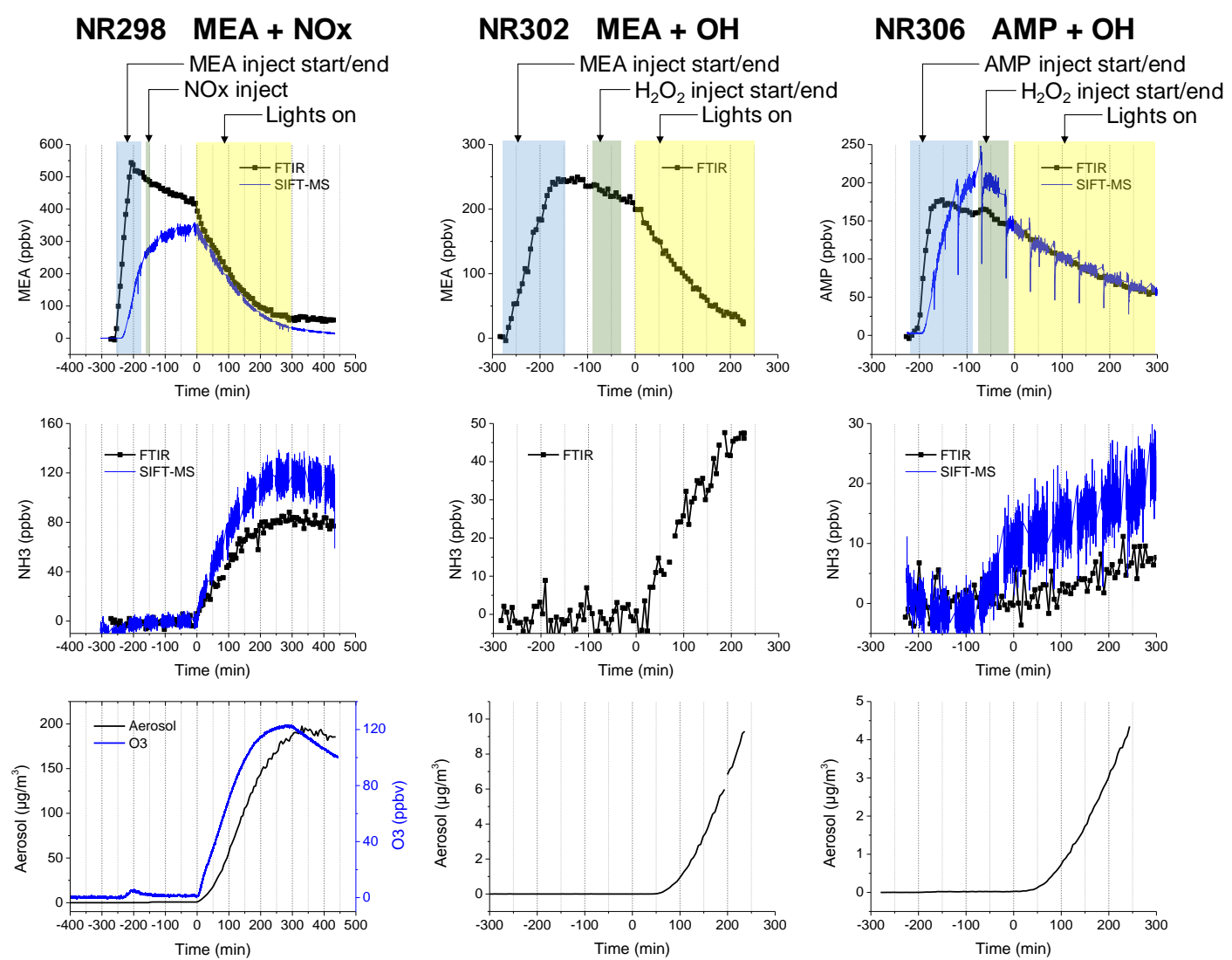

Figure S3 Time-dependent variation of measured amines, $\mathrm{NH}_{3}$, aerosol and $\mathrm{O}_{3}$ from $\mathrm{MEA}+\mathrm{NOx}(\mathrm{NR} 298), \mathrm{MEA}+\mathrm{H}_{2} \mathrm{O}_{2}(\mathrm{NR} 302)$ and $\mathrm{AMP}+\mathrm{H}_{2} \mathrm{O}_{2}(\mathrm{NR} 306)$ experiments.

The injection durations of amines, $\mathrm{NOx}$ and $\mathrm{H}_{2} \mathrm{O}_{2}$ are marked by shaded areas 

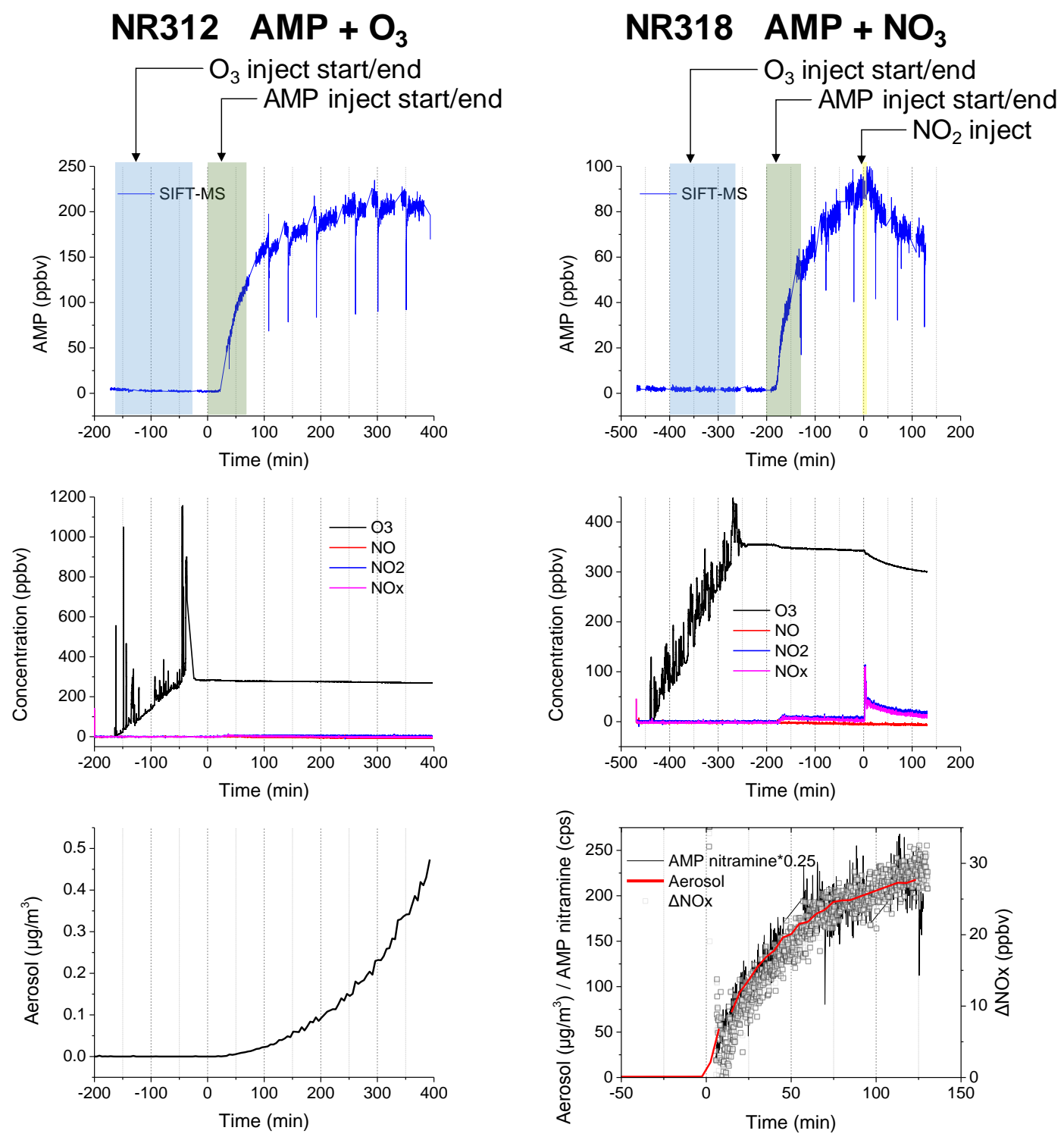

Figure S4 Time-dependent variation of measured AMP, NOx, $\mathrm{O}_{3}$, and AMP nitramine from $\mathrm{AMP}+\mathrm{O}_{3}(\mathrm{NR} 312)$ and $\mathrm{AMP}+\mathrm{NO}_{3}(\mathrm{NR} 318)$ experiments. The injection durations of $\mathrm{O}_{3}, \mathrm{AMP}$ and $\mathrm{NO}_{2}$ are marked by coloured shading 


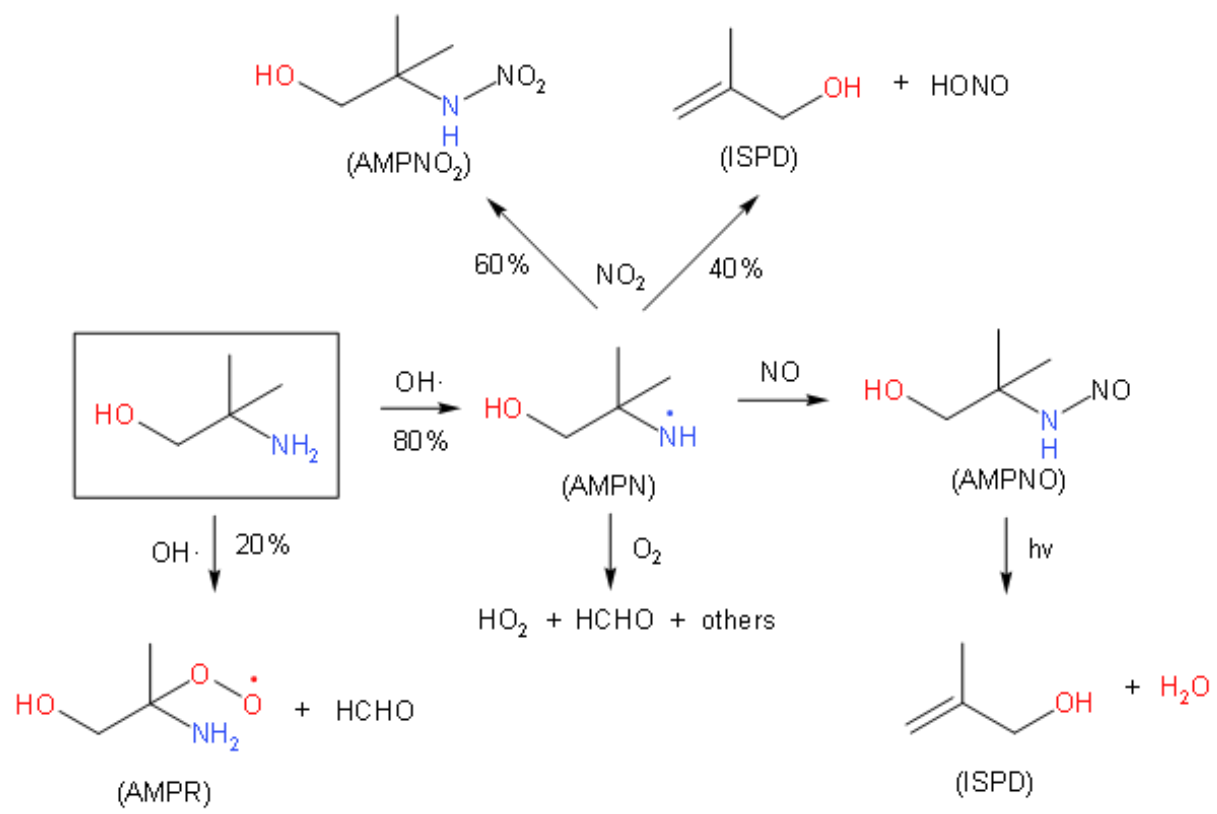

Figure S5 The proposed CSIAMP-19 mechanism 
- chamber data - CB6 (base) - SAPRC-11 (base)
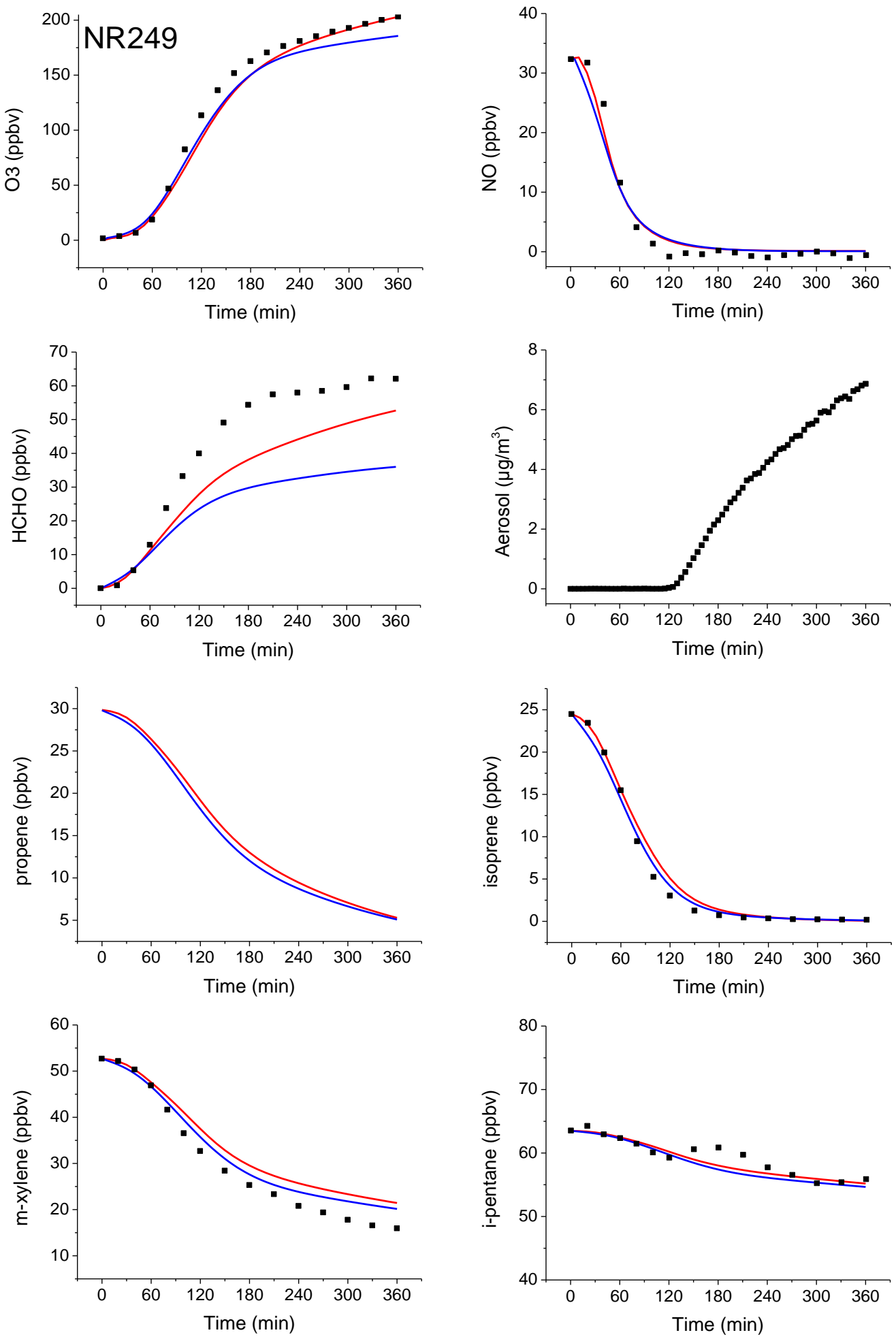

Figure S6 VOC-NOx (NR249) experimental and modeled data. The aerosol wall-loss has been corrected 
- chamber data
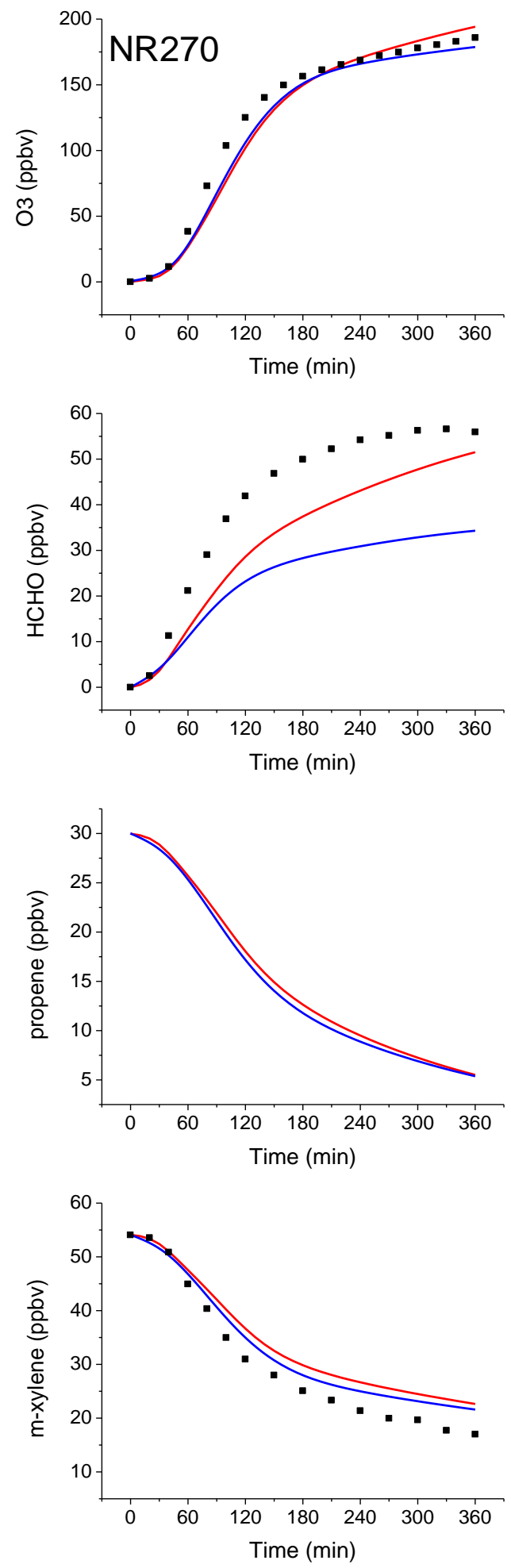

SAPRC-11 (base)
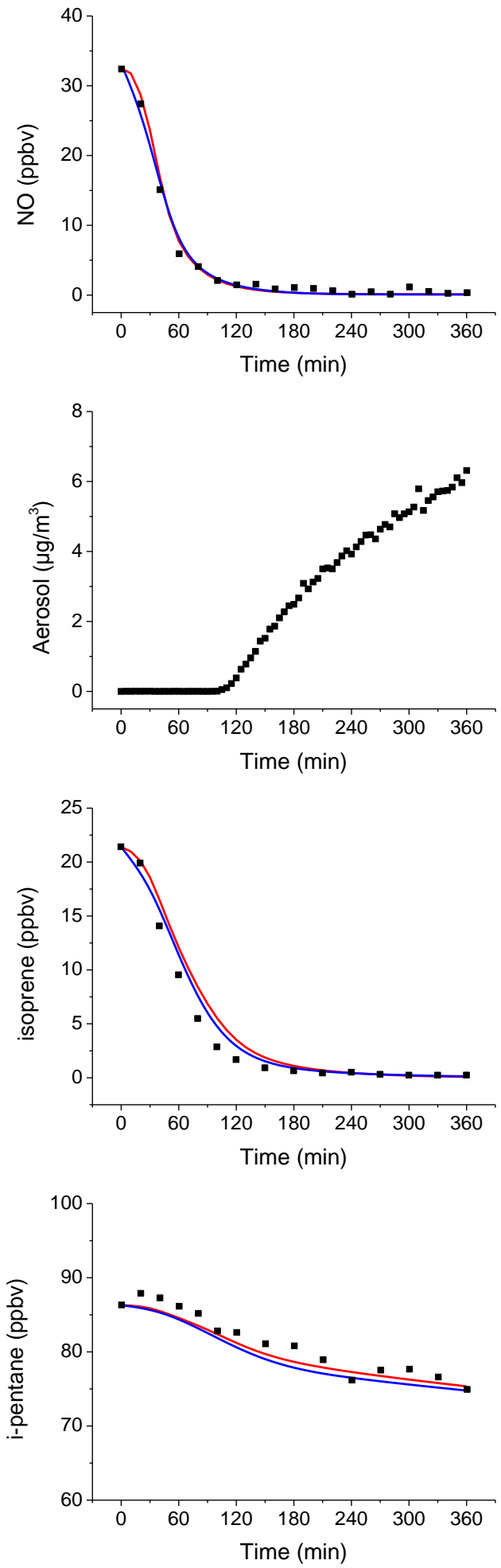

Figure S7 VOC-NOx (NR270) experimental and modeled data. The aerosol wall-loss has been corrected 
- chamber data
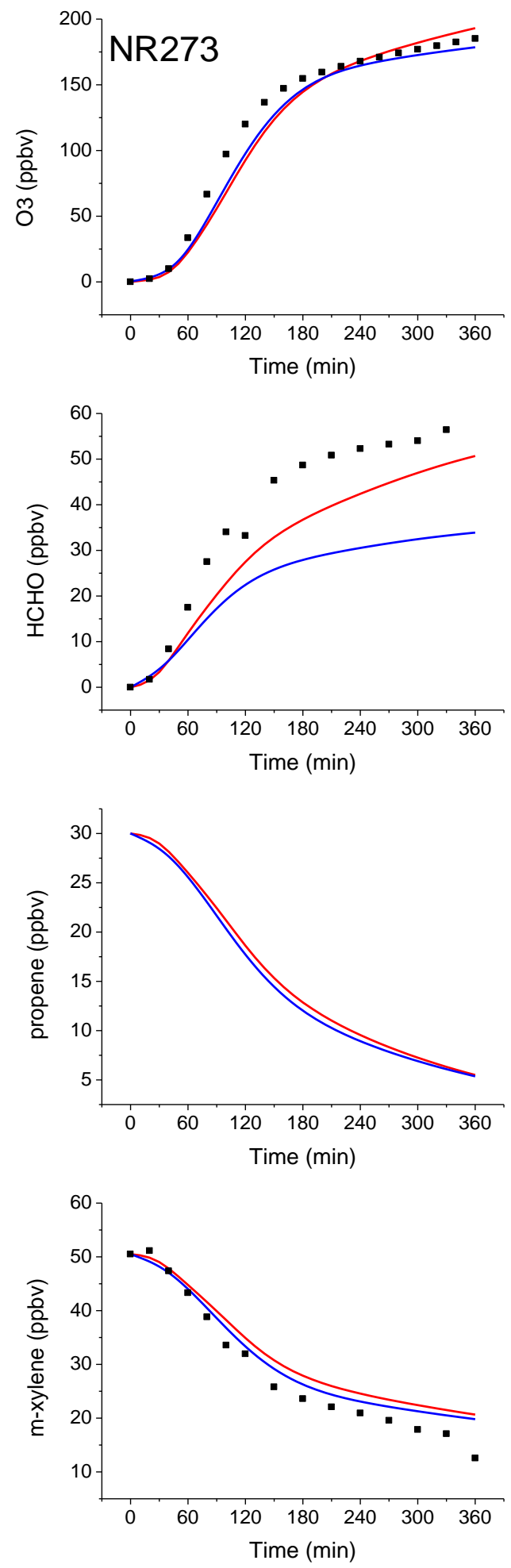

SAPRC-11 (base)
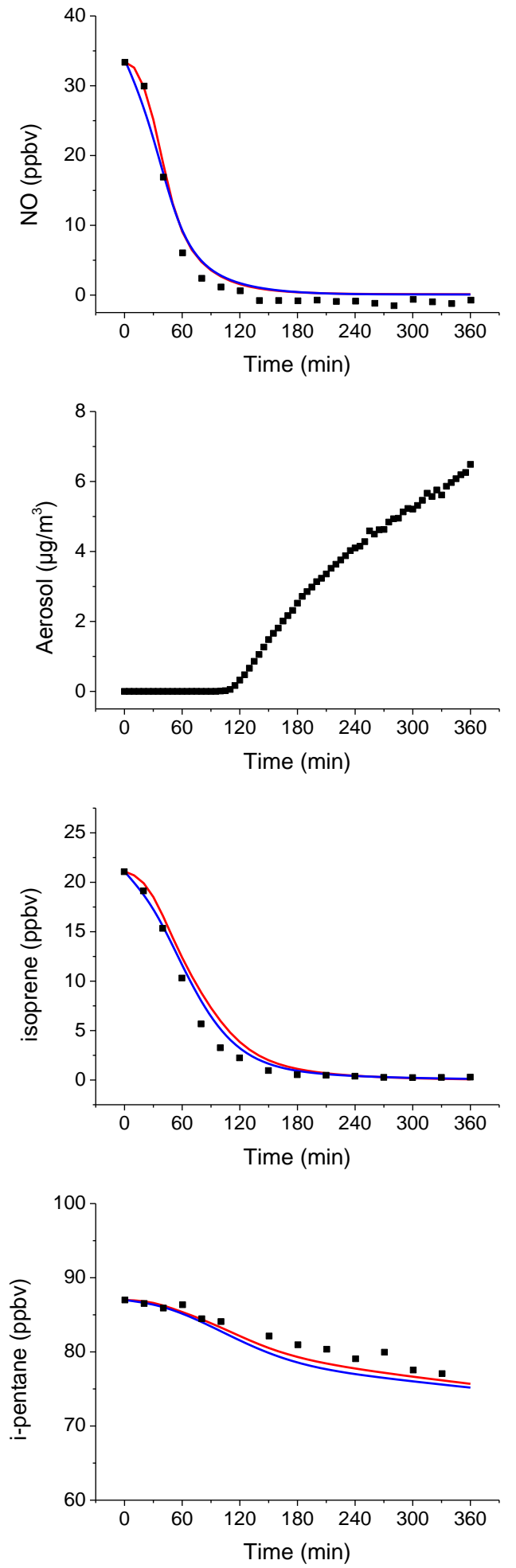

Figure S8 VOC-NOx (NR273) experimental and modeled data. The aerosol wall-loss has been corrected 
- chamber data CB6 (base)

SAPRC-11 (base)
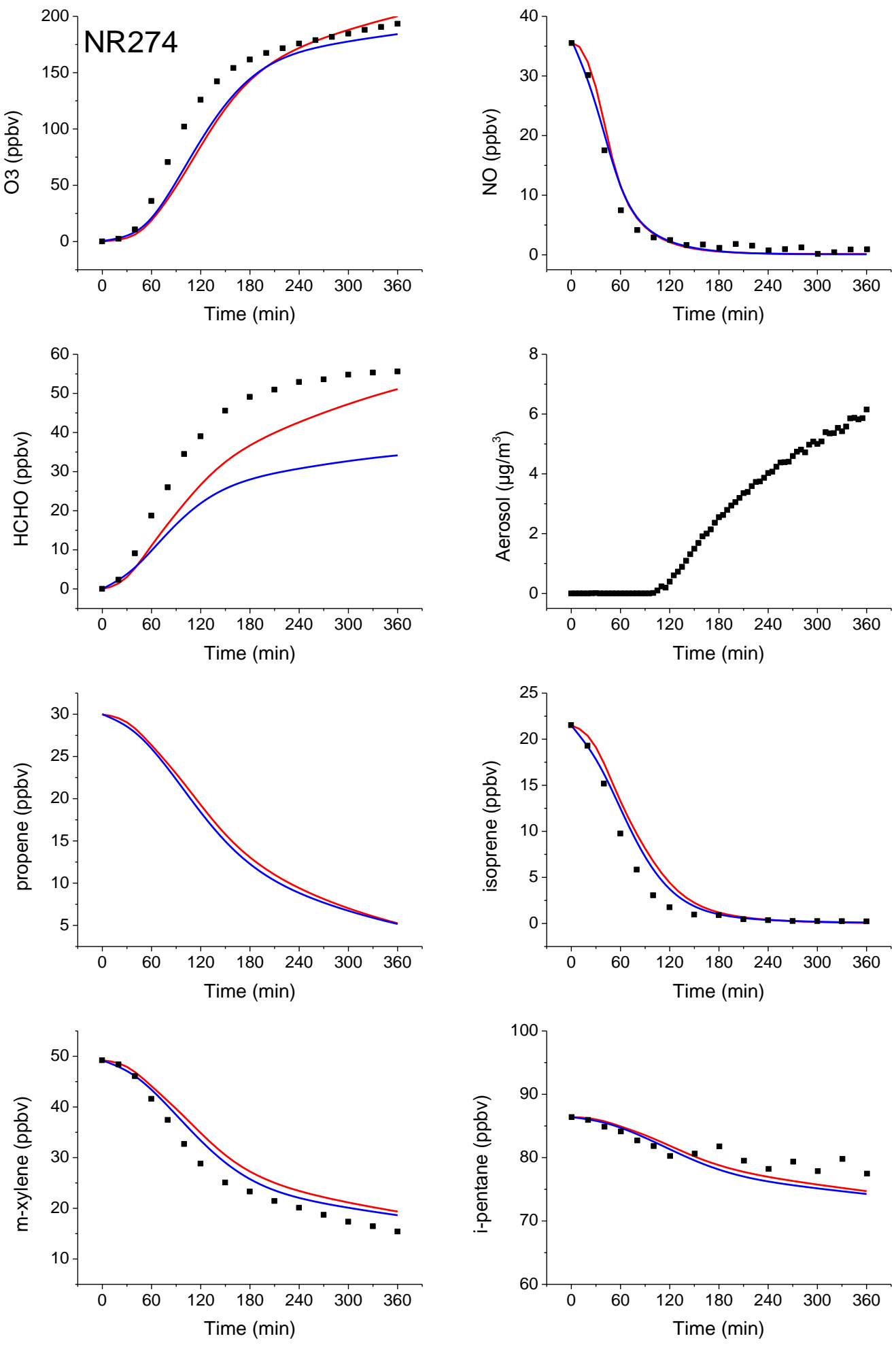

Figure S9 VOC-NOx (NR274) experimental and modeled data. The aerosol wall-loss has been corrected 
- chamber data CB6 (base)

SAPRC-11 (base)
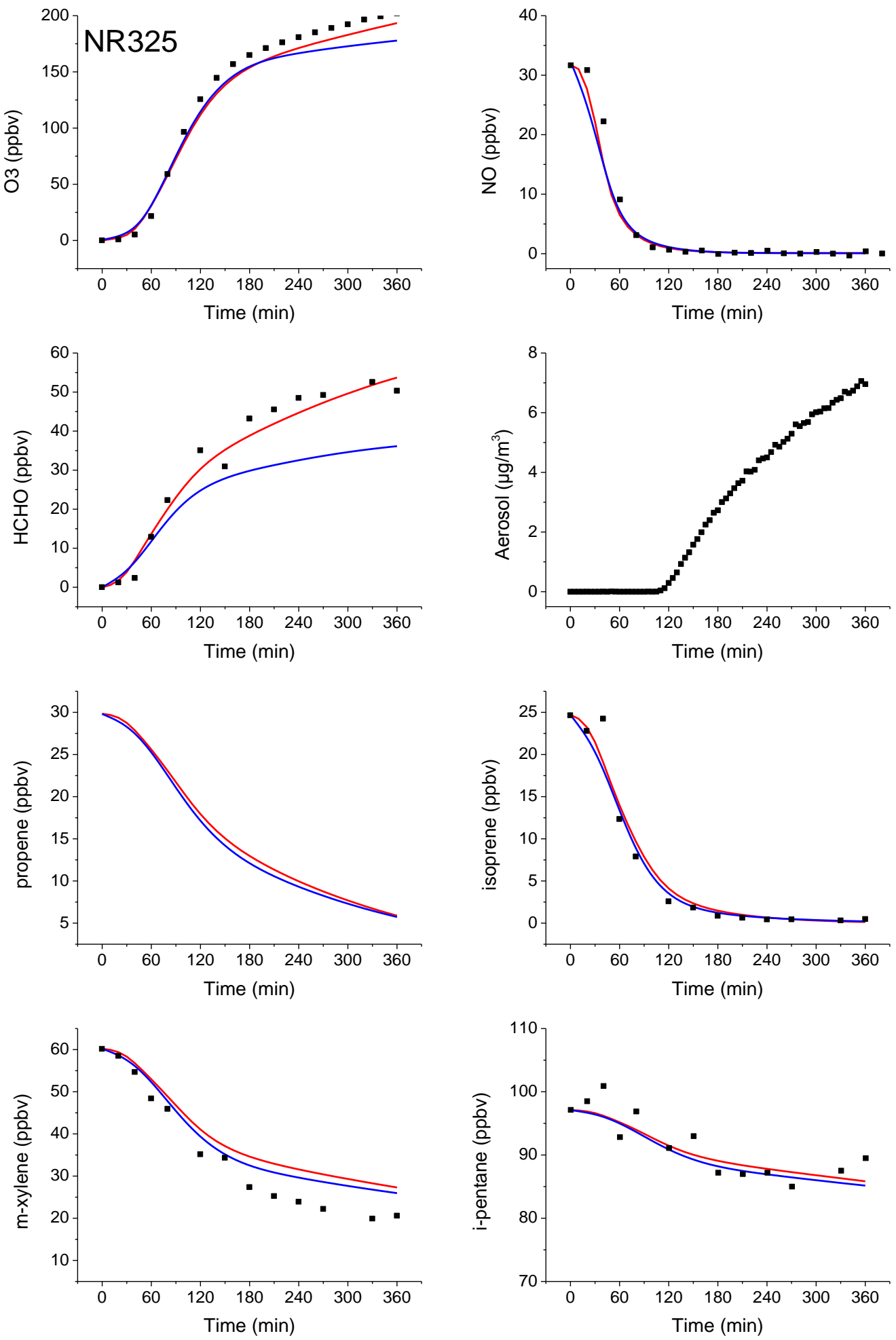

Figure S10 VOC-NOx (NR325) experimental and modeled data. The aerosol wallloss has been corrected 

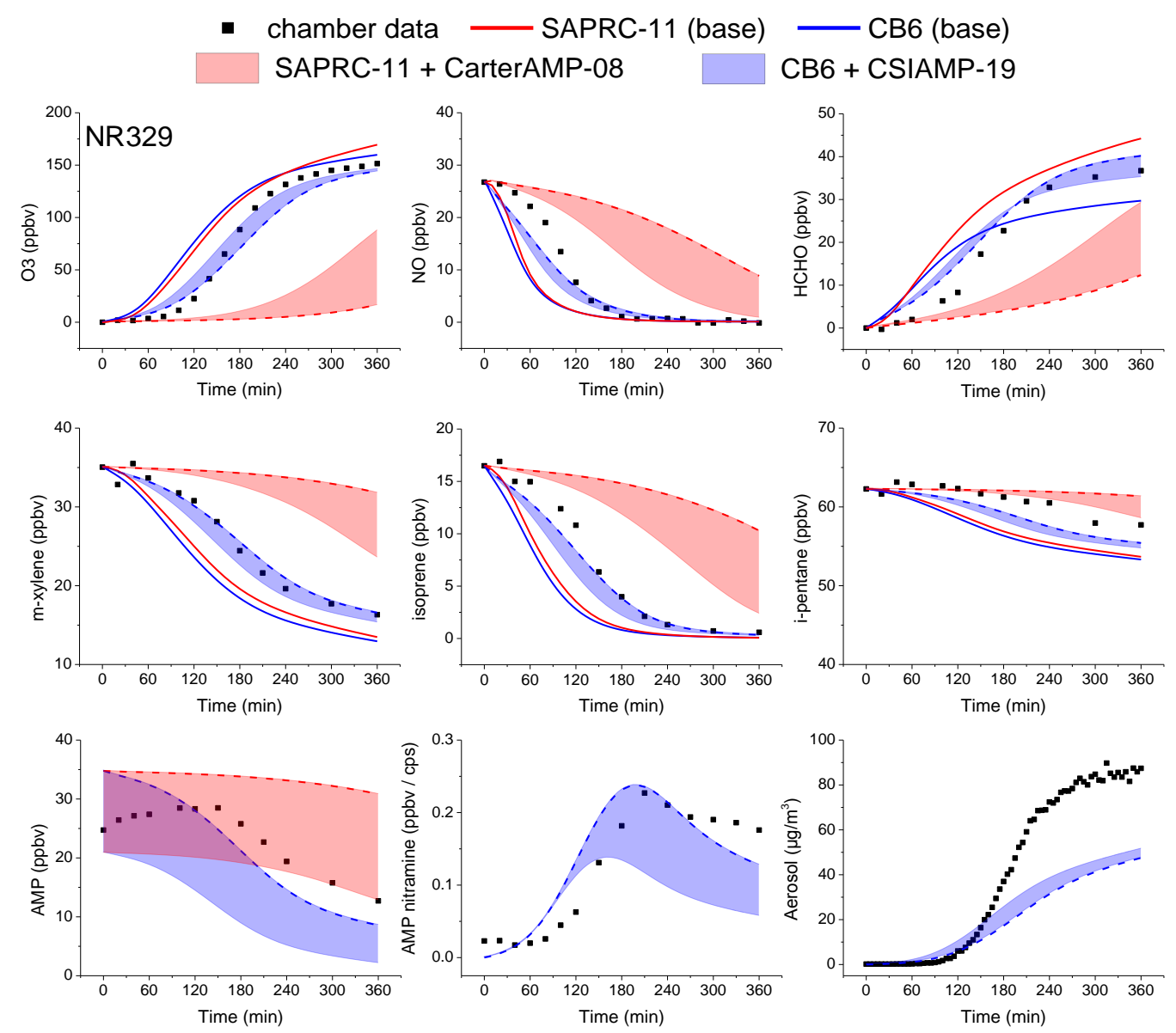

Figure S11 AMP-VOC-NOx (NR329) experimental and modeled data. The shaded area represents initial AMP concentration estimated from 60 to $100 \%$ injection. The dashed line (overlapped to one side of shaded area) represents initial AMP concentration estimated from 100\% injection. The measured AMP nitramine was raw signal (cps, count per second) of $164^{+}\left(\mathrm{NO}^{+}\right)$ion obtained from SIFT-MS and was normalized by multiplying a factor of 0.002 . The wall-loss corrected aerosol mass and modeled AMP nitrate salt (AMPNTR) are also shown 
- chamber data SAPRC-11 (base)
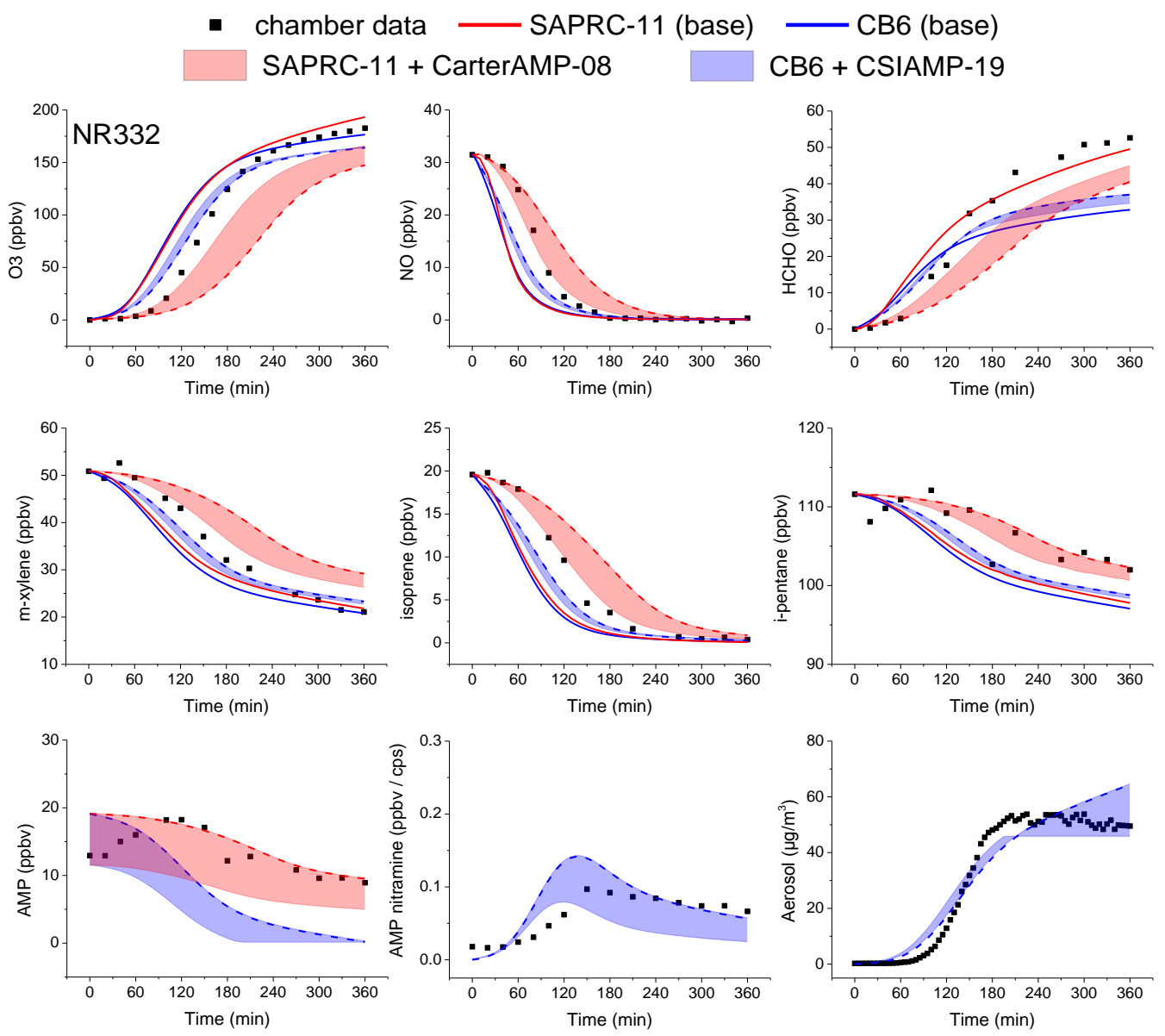

Figure S12 AMP-VOC-NOx (NR332) experimental and modeled data. The shaded area represents initial AMP concentration estimated from 60 to $100 \%$ injection. The dashed line (overlapped to one side of shaded area) represents initial AMP concentration estimated from $100 \%$ injection. The measured AMP nitramine was raw signal (cps, count per second) of $164^{+}\left(\mathrm{NO}^{+}\right)$ion obtained from SIFT-MS and was normalized by multiplying a factor of 0.002 . The wall-loss corrected aerosol mass and modeled AMP nitrate salt (AMPNTR) are also shown 

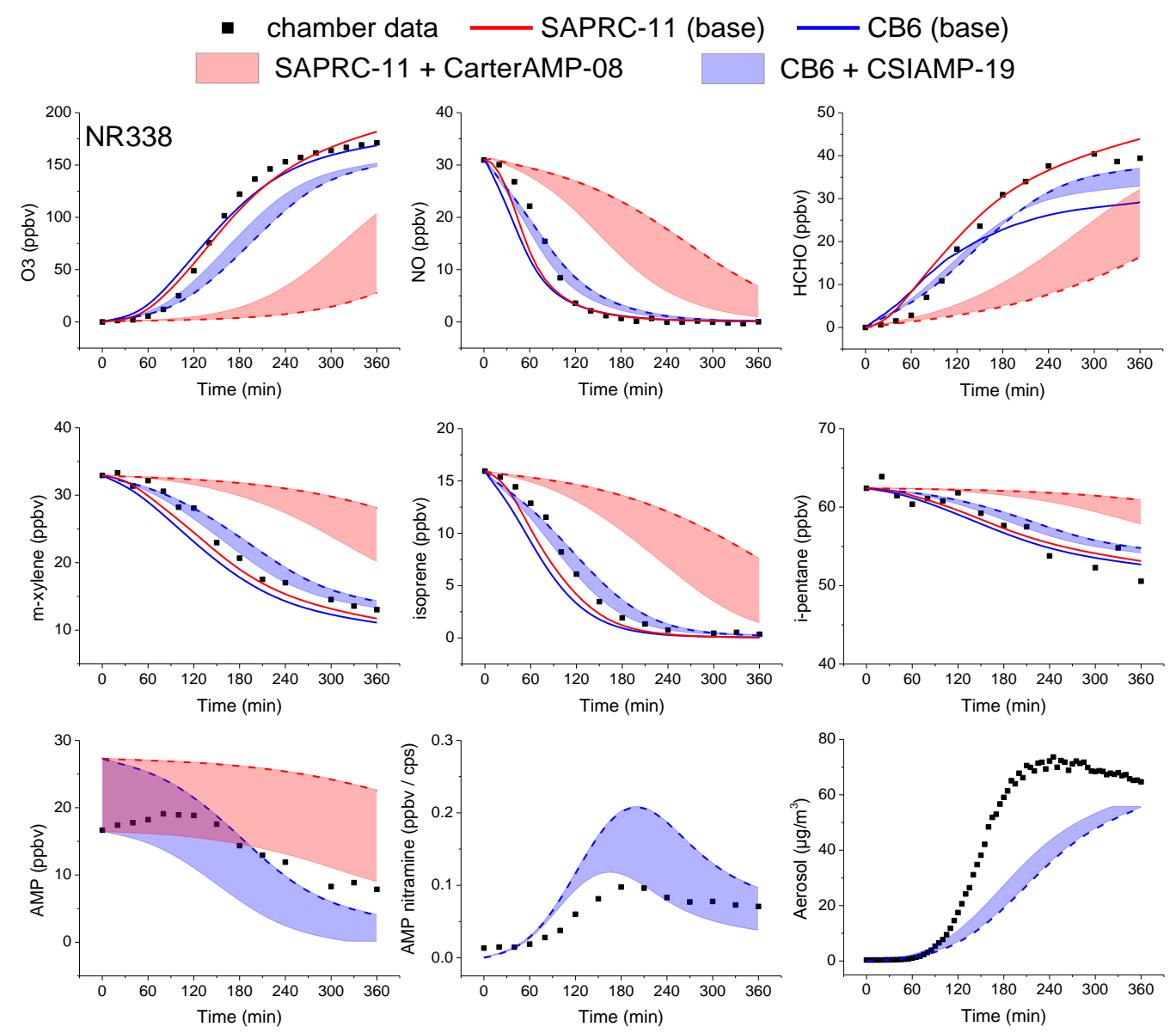

Figure S13 AMP-VOC-NOx (NR338) experimental and modeled data. The shaded area represents initial AMP concentration estimated from 60 to $100 \%$ injection. The dashed line (overlapped to one side of shaded area) represents initial AMP concentration estimated from 100\% injection. The measured AMP nitramine was raw signal (cps, count per second) of $164^{+}\left(\mathrm{NO}^{+}\right)$ion obtained from SIFT-MS and was normalized by multiplying a factor of 0.002 . The wall-loss corrected aerosol mass and modeled AMP nitrate salt (AMPNTR) are also shown 


\section{References}

(1) Angove, D.; Azzi, M.; Tibbett, A.; Campbell, I. An Investigation into the Photochemistry of Monoethanolamine (MEA) in NOx. ACS Symposium Series - Recent Advances in PostCombustion CO2 Capture Chemistry. 2012, 1097 (Chapter 14), 265-273.

(2) Angove, D.; White, S.; Tibbett, A.; Campbell, I.; Emmerson, K.; Cope, M.; Patterson, M.; Feron, P.; Azzi, M. Environmental Impacts of Amine-based CO2 Post Combustion Capture (PCC) Process. Deliverable 4.2: Determination of the fate of PCC emissions into the atmosphere. Prepared for: ANLEC R\&D. CSIRO, Australia.2013.

(3) Azzi, M.; Angove, D.; Campbell, I.; Cope, M.; Emmerson, K.; Feron, P.; Patterson, M.; Tibbett, A.; White, S. Assessing Atmospheric Emissions from an Amine-based CO2 Post-combustion Capture Processes and their Impacts on the Environment - A Case Study. Volume 2: Atmospheric chemistry of MEA and 3D air quality modelling of emissions from the Loy Yang PCC plant. 2014.

(4) Smith, D.; Španěl, P. Selected ion flow tube mass spectrometry (SIFT-MS) for on-line trace gas analysis. Mass Spectrom. Rev. 2005, 24 (5), 661-700.

(5) Harris, G.W.; Pitts, J.N. Rates of Reaction of Hydroxyl Radicals with 2-(Dimethylamino)ethanol and 2-Amino-2-methyI-1 -propanol in the Gas Phase at $300 \pm 2$ K. Environ. Sci. Technol. 1983, 17 (1), 50-51.

(6) Onel, L.; Blitz, M.A.; Seakins, P.W. Direct Determination of the Rate Coefficient for the Reaction of OH Radicals with Monoethanol Amine (MEA) from 296 to $510 \mathrm{~K}$. The Journal of Physical Chemistry Letters. 2012, 3 (7), 853-856.

(7) Nielsen, C.J.; Herrmann, H.; Weller, C. Atmospheric chemistry and environmental impact of the use of amines in carbon capture and storage (CCS). Chem. Soc. Rev. 2012, 41 (19), 6684.

(8) White, S.; Angove, D.; Li, K.; Campbell, I.; Element, A.; Halliburton, B.; Lavrencic, S.; Cameron, D.; Jamie, I.; Azzi, M. Development of a new smog chamber for studying the impact of different UV lamps on SAPRC chemical mechanism predictions and aerosol formation. Environ. Chem. 2018, 15 (3), 171.

(9) Borduas, N.; Abbatt, J.P.D.; Murphy, J.G. Gas Phase Oxidation of Monoethanolamine (MEA) with OH Radical and Ozone: Kinetics, Products, and Particles. Environ. Sci. Technol. 2013, 47 (12), 6377-6383.

(10) Carter, W.P.L. Reactivity estimates for selected consumer product compounds. Final report to the California Air Resources Board, Contract No. 06-408. 2008.

(11) Karl, M.; Dye, C.; Schmidbauer, N.; Wisthaler, A.; Mikoviny, T.; Amp, D.; Apos; Anna, B.; Müller, M.; Borrás, E.; Clemente, E.; Muñoz, A.; Porras, R.; Ródenas, M.; Vázquez, M.; Brauers, T. Study of OH-initiated degradation of 2-aminoethanol. Atmos. Chem. Phys. 2012, 12 (4), 18811901.

(12) Ge, X.; Wexler, A.S.; Clegg, S.L. Atmospheric amines - Part II. Thermodynamic properties and gas/particle partitioning. Atmos. Environ. 2011, 45 (3), 561-577. 
(13) Salo, K.; Westerlund, J.; Andersson, P.U.; Nielsen, C.; D Anna, B.; Hallquist, M. Thermal Characterization of Aminium Nitrate Nanoparticles. The Journal of Physical Chemistry A. 2011, 115 (42), 11671-11677.

(14) Qiu, C.; Zhang, R. Multiphase chemistry of atmospheric amines. Phys. Chem. Chem. Phys. 2013, 15 (16), 5738-5752.

(15) Murphy, S.M.; Sorooshian, A.; Kroll, J.H. Secondary aerosol formation from atmospheric reactions of aliphatic amines. Atmos. Chem. Phys. 2007, 7 (9), 2313-2337.

(16) Carter, W.P.; Heo, G. Development of revised SAPRC aromatics mechanisms. Atmos. Environ. 2013, 77, 404-414.

(17) Yarwood, G.; Whitten, G.; Jung, J. Development, Evaluation and Testing of Version 6 of the Carbon Bond Chemical Mechanism (CB6). Final Report Prepared for Texas Commission on Environmental Quality. 2010.

(18) Antonsen, S.; Bunkan, A.J.; D'Anna, B.; Eichler, P.; Farren, N.; Hallquist, M.; Hamilton, J.F.; Kvarnliden, H.; Mikoviny, T.; Müller, M.; Nielsen, C.J.; Stenstrøm, Y.; Tan, W.; Wisthaler, A.; Zhu, L. Atmospheric chemistry of tert-butylamine and AMP (Poster GHGT-13). Available at www.mn.uio.no/kjemi/english/research/projects/aca/publications-and-presentations/. 2017. 